\title{
Seeding Performance Simulations and Experiments for a Spoon- Wheel Type Precision Cottonseed-Metering Device Based on EDEM
}

\author{
Yudao LI ${ }^{1,2,3}$ and Shulun XING ${ }^{1}$, Shasha LI $^{1}$, Li LIU $^{4}$, Xiaohui ZHANG ${ }^{1,2,3}$, Zhanhua SONG ${ }^{1,2,3^{*}}$, Fade LI $^{1,2,3^{*}}$
}

1 Shandong Agricultural University, Taian, Shandong 271018, China;

2 Shandong Provincial Key Laboratory of Horticultural Machinery and Equipment, Taian, Shandong 271018, China;

3 Shandong Provincial Engineering Laboratory of Agricultural Equipment Intelligence, Taian, Shandong 271018, China;

4 Shandong University, Jinan, Shandong 250061, China.

\section{*Corresponding Author: Zhanhua SONG, E-mail: songzh6688@163.com; Fade LI, E-mail: lifade@sdau.edu.cn}

\begin{abstract}
:
To study the effects of seed metering on seeding performance under different motion parameters, a simulation model for a spoonwheel type seeder was established. A seed meter was tested by using EDEM (Engineering Discrete Element Method) software to simulate its working process at different speeds and tilt angles. The trajectories of individual cottonseeds in the seed-metering device were obtained, concurrently, the stress trend in the grain group was determined as a function of time. The simulation results suggest that at larger speeds, the metering index of the seed meter gradually decreases, while the index and the missing index gradually increase. As the tilt angle increased, the multiples index and missing index gradually decreased, while the multiples index gradually increased. When the seed meter speed reached $50 \mathrm{r} / \mathrm{min}$ and the tilt angle was $15^{\circ}$, the seed meter had a relatively good working performance with a seed spacing acceptance index of $92.59 \%$, a multiples index of $1.85 \%$, and a missing rate index of $5.56 \%$. The seed meter was tested on a bench by using a JPS-12 performance-tester bench. At the aforementioned speed and angle, the coefficient of variation for the cottonseed spacing was $2.1 \%$. The field trial results indicated that the multiples and the missing rates were higher than those for the tester bench but still met a passing rate of more than $90 \%$. The coefficient of variation for the seed spacing was less than $10 \%$, suggesting that the design could be used for field sowing. The resulting seeding uniformity was higher under these conditions, which indicates that the seed meter has a better working performance and the bench has a good seeding effect.
\end{abstract}

Keywords: spoon-wheel type seeder; EDEM simulation; tester bench; field trial; cottonseed

\section{Introduction}

An inevitable trend in the development of modern agriculture in China is the modernization of agricultural machinery and equipment to promote land productivity ${ }^{[1]}$. A seed metering device is a key planting component, enabling related research to be implemented to facilitate precise cotton sowing. To date, there are two types of precision seed metering devices: pneumatic ${ }^{[2-4]}$ and mechanical. A pneumatic device has low requirements for the shape uniformity of the seed and can be applied to high-speed operations; however, the internal structure is complicated and the maintenance is expensive ${ }^{[5]}$. A mechanical seed meter has a simple structure, is convenient to manufacture, and has low costs. To date, scholars have conducted indepth theoretical analyses for mechanical precision seed- metering devices while optimizing the meter. To enhance the uniformity of the spoon-wheel type metering device, Wang et al. ${ }^{[6]}$ designed a cushioning device to reduce the impact velocity of the seed in the seeding tube. Wang et al. designed a combined curved-type retracting spoon for applications as a spoon-type seed metering device ${ }^{[7]}$. Simulation analyses and experimental verifications have shown that its working performance is good and can meet the requirements of precision cotton-seeding.

Zhang et al. simulated the gas-solid flow in an insidefilling air-blowing maize precision seed-metering device ${ }^{[8]}$, performed by means of a coupling approach of EDEM and computational fluid dynamics (CFD). The qualified rate of the optimized seed-metering device was greater than $93 \%$ when the working pressure was above $5.5 \mathrm{kPa}$, 
with a working speed lower than $10 \mathrm{~km} / \mathrm{h}$ throughout the experiment. The results indicated that the EDEM-CFD coupling approach was a reliable instrument for simulating the physical phenomenon of seed movement in an airflow field.

When the spoon-wheel type cottonseed metering device works, the movement parameters affect the movement of the cottonseeds, which affects the metering quality. To improve the quality of the metering, the optimal working parameters of the device were studied by using both simulations and experiments under different motion parameters. It is understood that non-delinted cottonseed is a bulk material based on the accepted definition of the term. To obtain an optimal combination of factors, the motion parameters of the de-stapled cottonseeds can be simulated by using EDEM software ${ }^{[9]}$, which is a multiobjective simulation package based on the discrete element method. Since the 1990s, scholars around the world have performed EDEM-based analyses on the relative motion of bulk materials and working parts ${ }^{[10-11]}$. Liao et al. performed EDEM-based analyses on the relative motion of bulk materials and working parts. A numerical study of gas-solid flow in the seed feeding device of an air-assisted centralized metering system was implemented by means of an EDEM and CFD coupling approach ${ }^{[12]}$.

Using the discrete element method, Van Liedekerke ${ }^{[13]}$ established a particle flow model with horizontal and inclined discs. Being experimentally verified, the experimental results were nearly consistent with the simulation results. Dun et al ${ }^{[14]}$ used the EDEM model on the structure of the wheel on a wheel-type seed metering disc to obtain the optimal parameters of the hole-diameter ratio and the inclination angle.

EDEM software was used here to simulate the working process of a spoon-wheel type cottonseed metering device. The motion law for cottonseeds under different characteristic parameters and their effects on the seeding performance of the metering device were studied to find the best relative motion characteristic parameters. Verifications of the tests were also implemented ${ }^{[15]}$.

\section{Structure and working principle of spoon- wheel type cottonseed metering device}

\subsection{Overall structure and working principle of meter}

As illustrated in Figure 1, the components of a spoonwheel type fine cottonseed metering device mainly include a speed-governing device, casing, guiding wheel, partition plate, seeding spoon wheel, and wall of seed hopper ${ }^{[16-17]}$. As depicted in Figure 2, the work of the seed metering device is divided into five processes: filling, clearing, delivering, guiding, and seeding the seeds.

Following is a description of the components of this device and how it works. Power is provided by the ground wheels. The transmission of power through a speedgoverning device drives the guiding wheel and seeding spoon-wheel to rotate in tandem. When the seeding spoon-wheel passes through the filling area and enters the clearing area, the excess cottonseeds in this wheel fall back to the filling area by the force of gravity, so that only one seed remains in the wheel. When the cottonseed moves to the delivery hole on the top of the partition plate, the seed falls into the seed-guide wheel through the opening on the partition plate; the guide wheel turns, carrying the seed through the guiding area to the seeding area; the seed leaves the metering device under the combined action of gravity, centrifugal force, friction and other forces to complete the delivery.

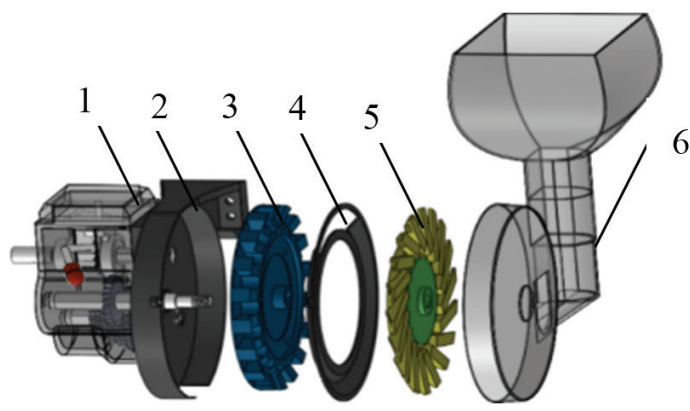

1. Speed governing device, 2. Casing, 3. Guiding wheel, 4. Partition plate, 5. Seeding spoon-wheel, 6 . Wall of seed hopper

Figure 1 Structural diagram of spoon-wheel type seed metering device

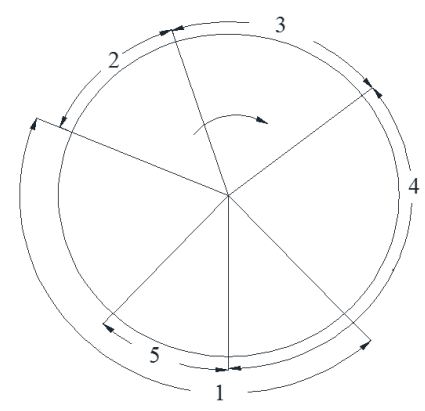

Areas: 1. Filling, 2. Clearing, 3. Delivery , 4. Guiding, 5. Seeding

Figure 2 Diagram of working principles of seed metering device

2.2 Design of critical structure for seed meter and critical speed calculation

As the key structure of the spoon-wheel type seed metering device is its wheel arrangement, the seeding work depends on the size of the inlet hole. Therefore, the empirical formula (1) is used to derive the diameter of the inlet hole to determine whether the seed meter can realize a precise row clock.

$d=k L_{\max }$

where $L_{\max }$ is the maximum size of the cottonseed after classification in $\mathrm{mm}$, and $k$ is a coefficient ranging from 1.1 to 1.3 .

The $k$ value is determined from the different wheel forms and seed sizes. When the seed length and width are nearly equal, $k$ takes a larger value. By measuring the size 
of the common seed with Shannongmian No. 11 cotton, the average length, width, and thicknesses are 10.07, 6.07, and $5.36 \mathrm{~mm}$, respectively; and the maximum grain size is the length value. The formula is obtained as $d=1.1 \times 10$ $=11 \mathrm{~mm}$. The width $\mathrm{b}$ of the spoon requires more than one-half of the seed length and less than 1.5 times the seed thickness, so that only one seed is in the spoon wheel. Based on previous measurements for the size of cottonseeds, the width of the seed spoon is set at $8 \mathrm{~mm}$.

During the seed-metering operation, if the linear speed of the spoons is too fast, it is difficult for the seed to overcome the centrifugal forces generated by the rotation and the friction between the wheel and the separator. Thus, the seed cleaning cannot be completed, thereby increasing the multiples rate. Concurrently, the high rotation speed reduces the seeding time; thus, the seed cannot enter the seeding wheel from the spoon-wheel, thereby resulting in a missed rate. The critical speed of the seed in suspension is then derived as

$V_{c}=\sqrt{g R}$

where $g$ is the gravitational acceleration at $9.8 \mathrm{~m} / \mathrm{s}^{2}$, and $R$ is the radius of the spoon-wheel in $\mathrm{m}$.

In general, the rotation speed of the seed meter is $70-80 \%$ of the critical speed to improve the cleaning and seeding efficiency. It is evident in Formula (2) that the larger the radius of the seed spoon-wheel, the greater the critical speed, which correspondingly improves the seeding efficiency. However, according to the structure of the metering device, the radius of the spoon-wheel should not be too large; therefore, its radius for this research was set at $0.119 \mathrm{~m}$, thus giving a critical speed of $1.08 \mathrm{~m} / \mathrm{s}$. The overall structure is illustrated in Figure 3.

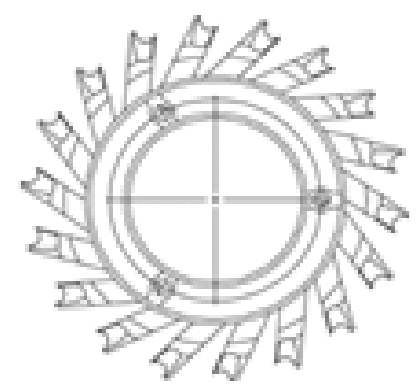

Figure 3 Schematic diagram of spoon wheel

\section{EDEM simulation analysis}

\subsection{Creating a simulation model}

EDEM software was used to simulate the working process of the seed meter ${ }^{[18-20]}$. The most basic step was to create a simulation model of a cottonseed, the shape of which is similar to an ellipsoid with one tapered end and one semispherical. The Hertz-Mindlin non-sliding contact model was selected because the surface of the seed is smooth and lacks adhesion ${ }^{[21]}$. Since it is difficult to accurately draw the shape of cotton kernels with drawing software, a method for splicing balls of different diameters was selected to establish a model of the grain by using a simulation approach, as depicted in Figure 4.

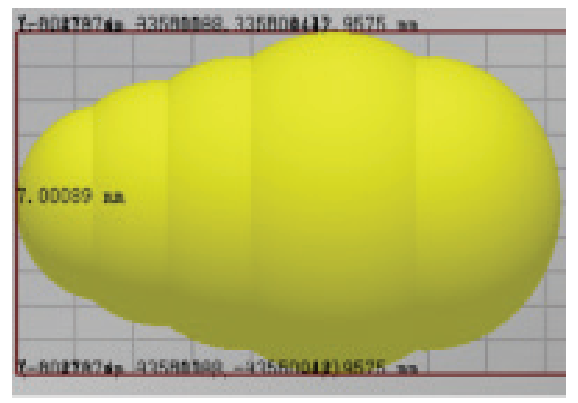

Figure 4 Schematic diagram of simulation model for cottonseeds

The external environment for grain movement is the spoon-wheel type seed geometry model. To reduce the simulation time, the $3 \mathrm{D}$ model of the meter removes the speed control device during the preservation process without affecting the simulation results ${ }^{[22]}$. The resulting structure is illustrated in Figure 5.

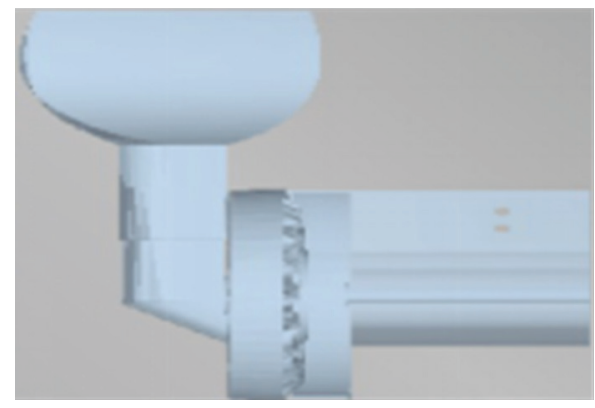

Figure 5 Schematic diagram of simulation model of the seed metering device

\subsection{Simulation calculations}

First, a fixed time step based on the Rayleigh time step is set. According to formula (3), the theoretical maximum for the time step in the EDEM simulated quasi-static particle set can be calculated as

$T_{R}=\pi R\left(\frac{\rho}{G}\right)^{\frac{1}{2}}(0.1631 \sigma+0.8766)^{-1}$

where $R$ is the particle radius in $\mathrm{mm} ; \rho$, the particle density in $\mathrm{g} / \mathrm{cm}^{3}$; $G$, the shear modulus in $\mathrm{Pa}$; and $\sigma$, Poisson's ratio.

In actual simulation operations, a percentage of the Rayleigh value is generally used for a fixed time step. In simulations where the number of contacts for a single particle is greater than 4 , it is appropriate to choose a fixed time step of 0.2 , which establishes a grid where the ideal side length of the grid element is twice the minimum particle radius of the simulation model, i.e., $2 \mathrm{~mm}$. Therefore, the minimum radius of the simulation model established in this research was set at $2 \mathrm{~mm}$. When the grid size is defined as twice the minimum radius of the model, the number of grid cells is large; thus, the grid size is set at 6.25 times the minimum radius. The total simulation duration defined according to the test requirements is $8 \mathrm{~s}$. The relevant parameter settings in the simulation calculation process are listed in Table 1. 
Table 3 Simulation process parameters

\begin{tabular}{lll}
\hline Project & Attribute value & Units \\
\hline Rayleigh step size & $3.42 \times 10^{-4}$ & $\mathrm{~s}$ \\
Fixed step size & $6.84 \times 10^{-5}$ & $\mathrm{~s}$ \\
Target save interval & 0.01 & $\mathrm{~s}$ \\
Total simulation time & 8 & $\mathrm{~s}$ \\
Minimum radius of particles & 2 & $\mathrm{~mm}$ \\
Grid size & 12.5 & $\mathrm{~mm}$ \\
Number of grids & 4056 & \\
\hline
\end{tabular}

\subsection{Single Factor Test}

\subsubsection{Simulation test of seed meter at different speeds}

After the cottonseed and seed meter simulation model had been created, the physical parameters and contact parameters were set, as listed in Tables 2 and 3.

Table 2 Material properties for simulation model

\begin{tabular}{cccc}
\hline Material & $\begin{array}{c}\text { Poisson's } \\
\text { ratio }\end{array}$ & $\begin{array}{c}\text { Shear modu- } \\
\text { lus }(\mathrm{MPa})\end{array}$ & Density $\left(\mathrm{kg} \cdot \mathrm{m}^{-3}\right)$ \\
\hline Seed & 0.25 & $1.0 \times 10^{10}$ & 860 \\
Wall & 0.28 & $8.2 \times 10^{10}$ & 7890 \\
\hline
\end{tabular}

Table 3 Material contact parameters of simulation model

\begin{tabular}{cccc}
\hline Contact parameter & $\begin{array}{c}\text { Collision } \\
\text { recovery } \\
\text { coefficient }\end{array}$ & $\begin{array}{c}\text { Static friction } \\
\text { factor }\end{array}$ & $\begin{array}{c}\text { Rolling friction } \\
\text { factor }\end{array}$ \\
\hline Seed - Seed & 0.30 & 0.56 & 0.15 \\
Seed -wall & 0.52 & 0.50 & 0.10 \\
\hline
\end{tabular}

Wang used the working speed as the influencing factor and analyzed it with EDEM software to obtain the spoon performance ${ }^{[23]}$. Concurrently, the design of the spoonwheel structure and the critical working speed determined in the previous study suggested that the working speed has a certain influence on the movement laws of cottonseeds and the seeding performance of the meter. In the present study, a single-factor simulation test for the rotational speed was established to explore the effects of different values on the performance of the metering device. During the simulation, the speed of the meter was set at 15, 20, 25, $30,35,40,45,50$, and $55 \mathrm{r} / \mathrm{min}$. The 0 th to the 1 st second constituted the seed generation time, after which the spoon-wheel and seeding wheel began to rotate.

3.3.2 Simulation Test of Seed Metering Device under Different Tilt angles

In a spoon-wheel type seed meter, a cottonseed can be cleaned by gravity. The meter has an inclination angle with respect to the ground that causes the seed to produce a force component in the gravitational direction, thereby affecting the cleaning process, as well as the movement laws of cottonseeds and seed-planting performance. Therefore, a single-factor simulation test of the tilt angle was constructed, in which the test was performed when the tilt angle was set at $0,5,10,15,20,25,30,35$, and $40^{\circ}$ with a rotation speed of $40 \mathrm{r} / \mathrm{min}$. The total simulation time was 8 seconds. The 0 to 1 st second constituted the seed generation time, after which the spoon-wheel and the seeding wheel began to rotate.

\section{Simulation Results and Analysis}

\subsection{Simulation analysis of cottonseed movement process}

During the simulation, the cottonseeds were statically generated at the pellet factory and then entered the filling area with a falling process depicted in Figure 6. The spoonwheel and seeding wheel began to rotate. The subsequent operation of the meter is illustrated in Figure 7. The different colors indicate the various seed speeds, and the arrows indicate the direction of the movement.
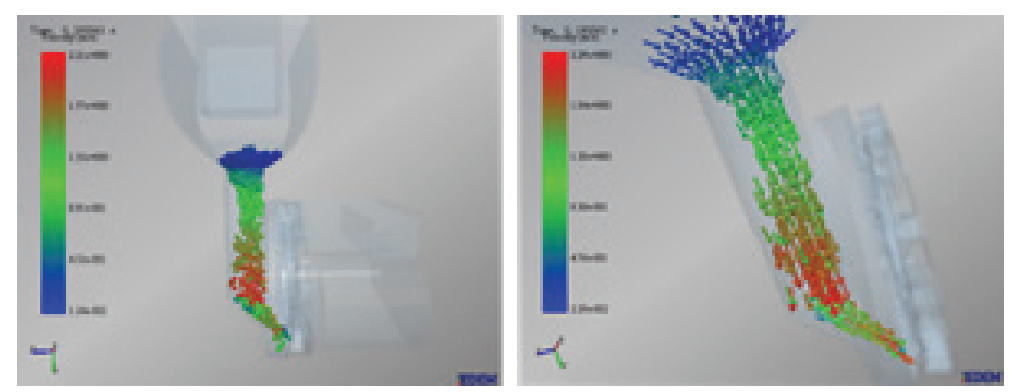

Figure 6 Schematic diagram of seed dropping process
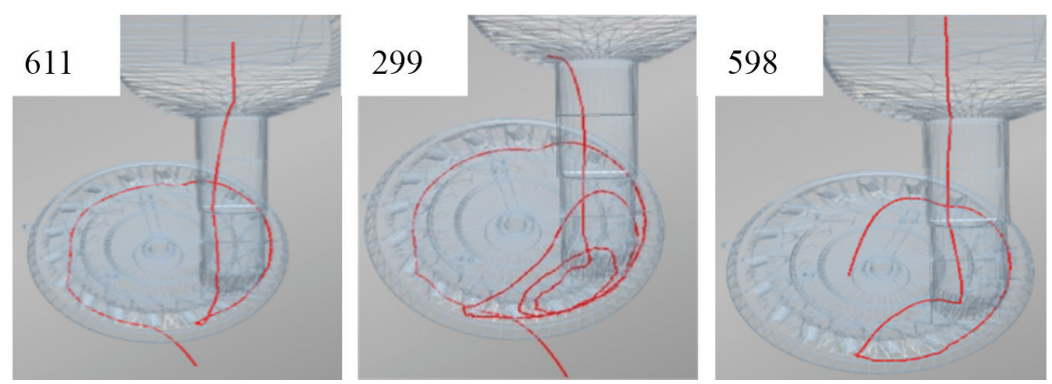

Figure 7 Schematic diagram for simulation process of seed metering device 

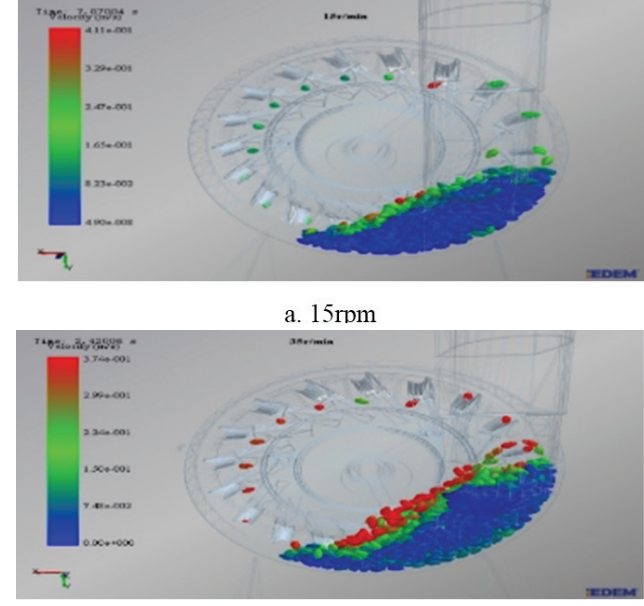

c. $35 \mathrm{rnm}$
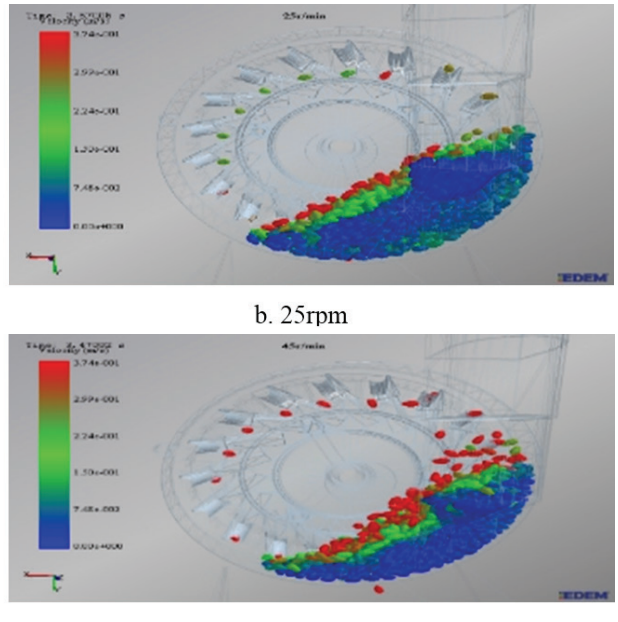

d. $45 \mathrm{rpm}$

Figure 8 Sketch of seeds 611, 299, and 598 for grain metering device

As depicted in Figure 8, the cottonseed movement during the post-simulation processing module was set for a streamlined display, in which the movement trajectory of the single seed in the meter can be clearly observed. Figure 7 is a schematic diagram illustrating the movement trajectory of a single seed when the rotation speed of the meter is set at $45 \mathrm{r} / \mathrm{min}$. Parts (a), (b), and (c) show the results for seed numbers 611,299 , and 598, respectively. During the operation of the metering device, model No. 611 had a shorter residence time in the filling area. The seed was picked up by the seeding wheel, after which process the grain entered the seeding port. After the seed was formed for No. 299, it was disturbed by the spoon-wheel in the filling area. After two rotational motions, it was picked up by the seeding wheel, followed by the movement of seed No. 611. After seed No. 598 was generated, it entered the filling area and was picked up by the seeding wheel. However, during the process, the seed failed to enter the wheel, thus causing the seed to be missed while the area was waiting for the next fill.

\subsection{Effect of seed meter speed on seeding performance}

During the simulation of the seed meter, higher rotation speeds caused the external force of the grain to change continuously. During the process of filling, clearing, delivering, and guiding seeds, collisions occurred between the metering device, the seed, and the wall, which caused missing and multiples during the operation of the device. The treatment and evaluation of the metering device are based on "Technical Conditions for a Single Grain (Precision) Planter" and GB/T 6973-2005 [24] "Test Method for a Single Grain (Precision) Planter," as listed in Table 4.

Table 4 Performance index of seed metering device at different rotational speeds

\begin{tabular}{lccccccccc}
\hline Rotational speed (rpm) & 15 & 20 & 25 & 30 & 35 & 40 & 45 & 50 & 55 \\
\hline Acceptance index (\%) & 100 & 100 & 100 & 100 & 97.22 & 97.22 & 94.44 & 92.59 & 87.96 \\
Multiples index (\%) & 0 & 0 & 0 & 0 & 0 & 0 & 0.93 & 1.85 & 2.78 \\
Missing index (\%) & 0 & 0 & 0 & 0 & 2.78 & 2.78 & 4.63 & 5.56 & 9.26 \\
\hline
\end{tabular}

Table 5 Performance index of seed metering device at different tilt angles

\begin{tabular}{lccccccccc}
\hline Simulation angle $\left({ }^{\circ}\right)$ & 0 & 5 & 10 & 15 & 20 & 25 & 30 & 35 & 40 \\
\hline Acceptance index (\%) & 97.22 & 98.14 & 97.22 & 98.15 & 92.59 & 81.48 & 75 & 65.74 & 54.63 \\
Multiples index (\%) & 0 & 0.93 & 0.93 & 1.85 & 7.41 & 18.52 & 25 & 34.26 & 45.37 \\
Missing index (\%) & 2.78 & 0.93 & 1.85 & 0 & 0 & 0 & 0 & 0 & 0 \\
\hline
\end{tabular}

The performance indicators for the precision seed metering device reveal the following three items: the grain distance qualified index $S$, the multiples index $D^{[25]}$, and the missing index $M$. These performance indexes are calculated as follows:

$$
\begin{aligned}
& S=\frac{n_{1}}{N} \times 100 \% \\
& D=\frac{n_{2}}{N} \times 100 \%
\end{aligned}
$$

$$
M=\frac{n_{0}}{N} \times 100 \%
$$

In the preceding formulas, $n_{0}$ is the number of air leaks; $n_{1}$, the single seed row number; $n_{2}$, the number of granules; and $N$, the number of theoretical rows.

During the simulation tests, a total of 108 grains of cotton were discharged under the theoretical condition of 6 times the circular motion. By using Formulas (4)-(6), the 
grain distance acceptance index $S$, the multiples index $D$, and the missing index $\mathrm{M}$ of the seed meter are obtained at different rotational speeds. The results are listed in Table 4 .

As indicated in Table 4, as the rotation speed increases, the metering index shows a downwards trend; thus, lower rotation speeds provide a better seed-metering effect. When the rotation speed is greater than or equal to $45 \mathrm{r} /$ min, the multiples index increases with the rotation speed. If both are less than $2 \%$, the performance requirements of the seed meter are met. When the rotation speed is less than $35 \mathrm{r} / \mathrm{min}$, the missing index of the seed meter is 0 , and the seeding effect is good. When the rotation speed is greater than $50 \mathrm{r} / \mathrm{min}$, the missing index is significantly increased, and the work performance deteriorates.

In the actual working process of a spoon-wheel type seed meter with a certain structural form, a higher rotational speed leads to a greater seed volume per unit time. This improves the working efficiency of the metering device while simultaneously increasing both the multiples and missing indexes. After considering the various factors, the relative optimum speed of the seed meter was determined to be $50 \mathrm{r} / \mathrm{min}$.

4.3 Influence of inclination angle of seed meter on seeding performance

Table 5 lists the simulation results for different inclination tilt angles for the seed meter. It is observed that as the inclination angle increases, both the acceptance and the missing indexes of the meter gradually decrease while the multiples index increases. When the inclination angle is less than $15^{\circ}$, the seed particle size acceptance index is maximized and fluctuates over a small range. When the meter speed is $50 \mathrm{r} / \mathrm{min}$ and the tilt angle is $0^{\circ}$, a leakage process occurs during the operation of the device, which leads directly to an occurrence of cavitation. Thus, proper re-play is beneficial to increase the seed germination rate. After considering the various factors, the relative optimum tilt angle of the metering device was determined to be $15^{\circ}$.

\section{Test verification}

The spoon-wheel type seeder test bench was built on the basis of the JPS-12 performance test benchmark. To verify the simulation results, the test material was selected from Shannongmian Cotton No. 11 cottonseeds with a smooth surface and no damage.

The distance required between cottonseeds is $10 \mathrm{~cm}$. On the basis of the simulation tests, when the metering speed is $50 \mathrm{r} / \mathrm{min}$ and the tilt angle is $15^{\circ}$, the meter is operating at a relatively optimal level; thus, the relevant parameters of the test bench should be adjusted and tested. After the metering device operates under stable conditions for 30 seconds, the power supply can be shut off, after which the distance between the discharged grains is measured, and the coefficient of variation is calculated, as listed in Table 6 .

Table 6 Test bench results from precision cotton-metering device

\begin{tabular}{llllllll}
\hline $\begin{array}{c}\text { Seed bed } \\
\text { speed } \\
(\mathrm{m} / \mathrm{s})\end{array}$ & $\begin{array}{c}\text { Metering } \\
\text { speed } \\
(\mathrm{r} / \mathrm{min})\end{array}$ & $\begin{array}{c}\text { Tilting } \\
\text { angles } \\
\left({ }^{\circ}\right)\end{array}$ & $\begin{array}{c}\text { Multiples } \\
\text { rate } \\
(\%)\end{array}$ & $\begin{array}{c}\text { Missing rate } \\
(\%)\end{array}$ & $\begin{array}{c}\text { Acceptant } \\
(\%)\end{array}$ & $\begin{array}{c}\text { Mean } \\
\text { spacing } \\
(\mathrm{cm})\end{array}$ & $\begin{array}{c}\text { Variation } \\
\text { coefficient } \\
(\%)\end{array}$ \\
\hline 1.5 & 50 & 0 & 0.2 & 2.1 & 97.7 & 9.8 & 3.4 \\
1.5 & 50 & 5 & 2.1 & 1.5 & 96.4 & 10.7 & 4.8 \\
1.5 & 50 & 10 & 4.5 & 0.9 & 94.6 & 10.4 & 5.1 \\
1.5 & 50 & 15 & 5.1 & 0.7 & 94.2 & 10.2 & 8.9 \\
\hline
\end{tabular}

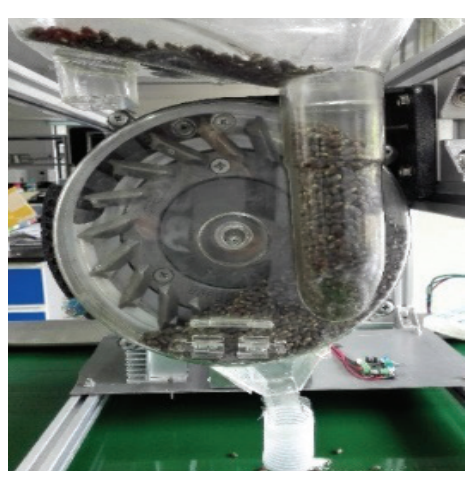

Figure 9 Test bench for precision cotton-metering device

When the belt speed of the seed bed is $1.5 \mathrm{~m} / \mathrm{s}$ and the rotation speed of the seed meter is $50 \mathrm{r} / \mathrm{min}$, the measured average grain distance is comparable to the specified grain distance. In this case, the coefficient of variation for the seed meter is small, indicating greater seed uniformity. When the tilt angle of the meter is $15^{\circ}$, the coefficient of variation for the grain distance of the seed meter is lower than the coefficient of variation at a tilt angle of $0^{\circ}$. This indicates that a tilt angle of $15^{\circ}$ leads to an improved metering performance. The simulations provide results that are nearly the same as the experiments, thus indicating that the test bench is adequate.

In June 2019, a field trial was conducted on a prototype at the Agricultural Research Station on the South Campus of Shandong Agricultural University (Figure 10).

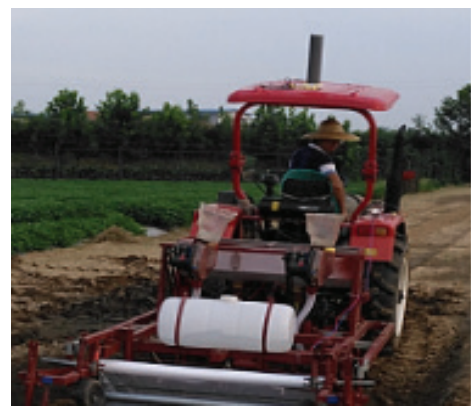

Figure 10 Field trial of precision cotton-metering 
The drive of the planter was a $26 \mathrm{~kW}$ Revo 350 tractor, working in loamy soil with a moisture content of $23.2 \%$. The instrumentation used in the tests mainly included cotton planters, rulers, stopwatches, moisture analyzers, and other related equipment. To measure the accuracy and convenience of the seed spacing, the sowing depth of the planter was adjusted to 0 at the time of sowing the seeds on the ground. Approximately 100 seed pitches were measured for each seeding length greater than 10 meters. The test results indicate that the machine can complete the relevant processes with a good seeding performance, during which single-seed precision sowing is realized with consistent spacing. The test results are listed in Table 7.

Table 7 Field trial results of precision cotton-metering

\begin{tabular}{ccccccc}
\hline $\begin{array}{c}\text { Sowing } \\
\text { speed }(\mathrm{m} / \mathrm{s})\end{array}$ & $\begin{array}{c}\text { Tilting angle } \\
\left({ }^{\circ}\right)\end{array}$ & $\begin{array}{c}\text { Multiples } \\
\text { rate }(\%)\end{array}$ & $\begin{array}{c}\text { Missing rate } \\
(\%)\end{array}$ & $\begin{array}{c}\text { Acceptance } \\
(\%)\end{array}$ & $\begin{array}{c}\text { Mean } \\
\text { spacing }(\mathrm{cm})\end{array}$ & $\begin{array}{c}\text { Variation } \\
\text { coefficient }(\%)\end{array}$ \\
\hline 1.5 & 0 & 0.3 & 2.9 & 96.8 & 10.7 & 3.6 \\
1.5 & 5 & 2.4 & 1.4 & 96.2 & 10.4 & 7.8 \\
1.5 & 10 & 4.7 & 1.1 & 94.2 & 9.8 & 5.6 \\
1.5 & 15 & 5.6 & 0.9 & 93.5 & 10.1 & 9.4 \\
\hline
\end{tabular}

The field trial results for the reactions in Table 7 suggest that the replay and leakage rates are higher than the test bench results, but still meet a passing rate of more than $90 \%$. The coefficient of variation for the grain distance is less than $10 \%$, meaning it can be used for field sowing. The reasons that the replay and leakage rates as well as the coefficient of variation of the grain distance are higher than the results of the test bench are the vibrations and soil moisture of the field trials.

The design and simulation results of the seed metering device were verified by a bench test and field trial. The results of the bench test and field trial were categorized according to the grain distance qualified index and the coefficient of variation. The grain distance obtained in the seed-metering device test ranged from 94.2-97.7\%; the coefficient of variation, from $3.4-8.9 \%$. The grain distance obtained in the field trial ranged from 93.5-96.8\%; the coefficient of variation, from 3.6-9.4\%. Zhang D X et al. tested the distance qualified index and the coefficient of variation for a precision maize seed-metering device. They found that the qualified rate of the optimized device was greater than $93 \%$. R.C. Singh et al. did some work on optimization of the design and operational parameters of a pneumatic seed-metering device for planting cottonseeds. Their metering system, with a speed of $0-42 \mathrm{~m} / \mathrm{s}$ and a vacuum pressure of $2 \mathrm{kPa}$, produced superior results with a feed index of $94.7 \%$ and a coefficient of variation ranging from $6-8 \%{ }^{[26-28]}$.

\section{Conclusion}

(1) The width of the seeding spoon was determined to be 8 $\mathrm{mm}$ based on the 3D size of the cottonseed. The structure and working principles of the meter indicate that its radius was $119 \mathrm{~mm}$, giving a total of $18 \mathrm{kinds}$ of spoons. The critical speed was calculated to be $1.08 \mathrm{~m} / \mathrm{s}$.

(2) EDEM software was used to simulate the seeding process of the meter at different speeds and inclination angles. According to the tests, when the meter speed achieved $50 \mathrm{r} / \mathrm{min}$ and the tilt angle was $15^{\circ}$, the meter exhibited a relatively good working performance. In this case, the grain distance acceptance index was $92.59 \%$; the multiples index, 1.85\%; and the missing index, 5.56\%.

(3) The seeding meter was tested on the bench and in the field. The test bench was considered for the meter through the PS-12 performance benchmark. For the simulation test bench, the seeding meter speed was $50 \mathrm{r} /$ min; the tilt angle, $15^{\circ}$. At this time, the coefficient of variation for the spacing of the discharged cottonseeds in the metering device was $2.1 \%$, the uniformity of which was high. The field trial results for the reactions indicated that the multiples and the missing rates were higher than in the test bench results but still met a passing rate of more than $90 \%$. The coefficient of variation in the seed spacing was less than $10 \%$, indicating that this design can be used for field sowing. This outcome suggests that the meter has a better working performance and is nearly consistent with the simulation results. Therefore, the test bench is considered to have a good seeding effect.

\section{References}

[1] Xu D. Research and Application of Wheat Precision Seeding Machinery[J]. Agricultural Science \& Technology and Equipment, 2015(06):79-80.

[2] Wang J W, Tang H, Wang J F, et al. Analysis and Experiment of Guiding and Dropping Migratory Mechanism on Pickup Finger Precision Seed Metering Device for Corn[J]. Transactions of the Chinese Society for Agricultural Machinery, 2017,48(01):29-37. (in Chinese)

[3] Wang J Q, Wang G, Xin N, et al. Simulation Analysis of Working Process and Performance of Cell Wheel Metering Device[J]. Transactions of the Chinese Society for Agricultural Machinery, 2011,42(12):83-87. (in Chinese)

[4] Liang S Y, Feng J, Zeng A J, et al. Performance Experiments of the Seed-Meter Device With Combined Suckers[J]. Transactions of the Chinese Society of Agricultural Engineering, 2001,17(02):84-87. (in Chinese)

[5] Arzu Yazgi, Adnan Degirmencioglu. Optimisation of The Seed Spacing Uniformity Performance of a Vacuum-type 
Precision Seeder Using Response Surface Methodology[J]. Biosystems Engineering, 2007,97(3):347-356.

[6] Wang Y, Wang F, Yin Y X, et al. Design of Spoon Type Seed Metering Device[J]. Journal of Anhui Agricultural Sciences, 2016,44(03):320-323. (in Chinese)

[7] Wang $X Y$, Wang J W, Tang $H$, et al. Improve Design and Experiment on Spoon of Spoon Precision Seed Metering Device [J]. Journal of Northeast Agricultural University, 2015, 46(12): 79-85.

[8] Han D D, Zhang D X, Jing H R, et al. DEM-CFD Coupling Simulation and Optimization of an Inside-filling Airblowing Maize Precision Seed-metering Device[J]. Computers and Electronics in Agriculture, 2018,150:426438.

[9] Chen T, Zhai C N, Xing ZZ, et al. Discrete Element Simulation Study of Seed Metering Process of Inside-Filling Meter Based on EDEM[J]. Journal of Anhui Agricultural Sciences, 2016,44(16),250-253+278. (in Chinese)

[10] Zhang X, Vu-Quoc L. Simulation of chute flow of soybeans using an improved tangential force-displacement model[J]. Mechanics of Materials,2000,32(2):115-129.

[11] Momozu M, Oida A, Yamazaki $M$, et al. Simulation of a soil loosening process by means of the modified distinct element method[J]. Journal of Terramechanics,2002,39(4):207-220.

[12] Lei X L, Liao Y T, Liao Q X . Simulation of Seed Motion in Seed Feeding Device with DEM-CFD Coupling Approach for Rapeseed and Wheat [J]. Computers and Electronics in Agriculture,2016,131:29-39.

[13] van Liedekerke P, Tijskens E, Dintwa E, et al . DEM simulations of the particle flow on a centrifugal fertilizer spreader[J] . Powder Technology,2009,190(3):348-360.

[14] Dun G Q, Chen H T, Zha S H, et al. Parameter Optimization and Validation of Soybean Cell Wheel Seeding Plate Type-hole Based on EDEM[J]. Soybean Science,2016,35(05),830-839.

[15] Wang Y, Yang X, Wang J H, et al. Simulation for Performance to Seed Cotton with Spoon-type Based on Discrete Element Method[J]. Journal of Shandong Agricultural University(Natural Science Edition),2016,47(06),873-878. (in Chinese)

[16] Brosh, T., Kalman, H., Levy, A., Peyron, I., Ricard, F.. DEM-CFD simulation of particle comminution in jet-mill. Powder Technol. , 2014,257, 104-112.

[17] Yuan G Z, Zhang T, Liu Y Q, et al. Design of a Spoon Wheel Type Seed Metering Device and Simulation of Soybean Seeds By Discrete Elemen[J]. Journal of Agricultural Mechanization Research,2017,11:25-29.

[18] Liu T, He R Y, Lu J, et al. Simulation and verification on seeding performance of nest hole wheel seed-metering device based on [J].Journal of South China Agricultural University,2017,11:25-29.(in Chinese)
[19] Shi S, Zhang D X, Yang L, et al. Simulation and verification of seed-filling performance of pneumatic-combined holes maize precision [J].Transactions of the Chinese Society of Agricultural Engineering, 2015,31(3) : 62-69. (in Chinese)

[20] Wang J W, Tang H, Wang Q, et al. Numerical simulation and experiment on seeding performance of pickup finger precision seed-metering device based on EDEM[J]. Transactions of the Chinese Society of Agricultural Engineering,2015,31(21) : 43-50.(in Chinese)

[21] Cao X Y, Liao Y T, Cong J L, et al. Design and Experiment on Metering Hole Structure of Centrifugal Precision Metering Device for Rapeseed[J].Transactions of the Chinese Society for Agricultural Machinery,2014,45,(S1):40-46. (in Chinese)

[22] Kamgar S, Eslami MJ, Maharlouie MM. Design, development and evaluation of a mechatronic transmission system to improve the performance of a conventional row crop planter. Intl J Agron Plant Prod, 2013,4(3):480-7.

[23] Wang X Y, Wang J W, Tang $\mathrm{H}$, et al. Improve design and experiment on spoon of spoon precision seed metering device[J].Journal of Northeast Agricultural University,2015,46(12):79-85.

[24] GB/T6973-2005 Single grain (precision) planter technical conditions. People's Republic of China machinery industry standard, 2005.(in Chinese)

[25] Shi L R, WuCJ M, Sun W, et al. Simulation test for metering process of horizontal disc precision metering device based on discrete [J].Transactions of the Chinese Society of Agricultural Engineering,2014,30(08):40-48. (in Chinese)

[26] R.C. Singh, G. Singh, D.C. Saraswat. Optimisation of design and operational parameters of a pneumatic seed metering device for planting cottonseeds [J]. Biosystems Engineering , 2005, 92 (4), 429-438.

[27]Yang, L., Yan, B.X., Cui, T., Yu, Y.M., He, X.T., Liu, Q.W., Liang, Z.J., Yin, X.W., Zhang,D.X.. Global overview of research progress and development of precision maize planters[J]. Int. J. Agri. Biol. Eng. , 2016, 9 (1), 9-26.

[28]Tong, Z.B., Zheng, B., Yang, R.Y., Yu, A.B., Chan, H.K.. CFD-DEM investigation of the dispersion mechanisms in commercial dry powder inhalers[J]. Powder Technol. , 2013,240, 19-24.

[29] Zhao, Y.Z., Ding, Y.I., Wu, C.N., Cheng, Y.. Numerical simulation ofhydrodynamics in downers using a CFDDEM coupled approach[J]. Powder Technol. , 2010199, 2-12.

[30] Li, H.C., Li, Y.M., Gao, F., Zhao, Z., Xu, L.Z.. CFD-DEM simulation of material motion in the air-and-screen cleaning device[J]. Comput. Electr. Agri. , 2012 b 88, $111-$ 119. 